\title{
Reflection on the Application-Type Nautical Education of Undergraduates in Shandong Province of China
}

\author{
Jiang Na, Zhang Qiang*, Dong Chuan-ming, Zhang Ning \\ Basic Education Department, Shandong Jiaotong University, Weihai, China \\ Email address: \\ zq20060054@163.com (Zhang Qiang) \\ ${ }^{*}$ Corresponding author \\ To cite this article: \\ Jiang Na, Zhang Qiang, Dong Chuan-ming, Zhang Ning. Reflection on the Application-Type Nautical Education of Undergraduates in \\ Shandong Province of China. Education Journal. Vol. 6, No. 1, 2017, pp. 22-27. doi: 10.11648/j.edu.20170601.13
}

Received: August 27, 2016; Accepted: December 19, 2016; Published: January 14, 2017

\begin{abstract}
The present thesis analyzes the necessity of the energetic development of the application-type nautical education of undergraduates in Shandong province and promotes some reflections on how to accelerate this development in combination with the opportunity and the current situation of the nautical education in Shandong province. The present thesis aims to elevate the quality of the nautical education of undergraduates in Shandong province, establish a Shandong who is well developed on coastal regions, develop the human resources strategy in coastal economic regions in Shandong Peninsula and provide reference for policy-making.
\end{abstract}

Keywords: Shandong, Application-Type, The Human Resources Strategy, Nautical Education, Undergraduate Education

\section{Introduction}

As a large marine province, Shandong province takes advantage over other areas on coastal regions, resources and technology. Under the background of national maritime strategy and " the Silk Road Economic Belt and the 21st-Century Maritime Silk Road" strategy, Shandong Province will fully develop the maritime industry [1]. There needs to be a support of talented people to establish coastal economic region in Shandong Peninsula. Provincial Party committee and Provincial government pointed out clearly that the resource of human talents is the most important resource in Instructions on How to Establish Coastal Economic Region in Shandong Peninsula. The rapid and all-round development of the nautical education of undergraduates in Shandong province is becoming the problem of human resources strategy that needs to be tackled with to establish the coastal regions under the provincial government's appeal for the development of mariners and coastal regions.

\section{The Opportunity to Develop the Nautical Education of Undergraduates in Shandong Province}

\subsection{Shipping Market Appeals for More Mariners}

Experts predict that the total demand of China's ocean resources will be more than 400 million people by 2020 [2].

In spite of the financial crisis and the slowing down of the shipping industry, the supply of mariners still falls out of demand and there is a great need for officers. According to the statistics and forecast of the authoritative institute, the demand of global mariners is $1,173,000$, in which officers take up 477,000 by 2020 . In order to meet the fleets growth and the economic development, it needs to increase 3.2 million senior mariners in the next ten years. There needs to be an increase $7.2 \%$ of mariners on the basis of that in 2010 [3]. At the same time, nautical education is in a changing world, therefore, to the continuity of the current education infrastructure for the maritime industry is very important. Wu Zhao-lin does some research on the connotation, the function and the status of nautical education in China [4]. The analysis in [5] is based on concepts from institutional economics, in particular governance of institutional structures, and which is 
applied to the Netherlands. The shortage of officers in international shipping market paves the way for the high-end marine talents in Shandong province to enter the international market.

\subsection{High-Level and High Diathesis Compound Talents Are Favorable Under the New Trend of Seafarer's Dispatch Onto Board Foreign-Owned Ships}

Because of the influence of global financial crisis, the mariners in countries like Philippines accept a reduction in salary and mariners in China do not take the advantage of low salary over other countries anymore. The upsizing and automation of ships poise a higher demand for marine talents. The high-level nautical education are researched by many abroad maritime institutions.[6-10]

This requires the officers to develop from skilled talents to compound talents who are qualified in skills, management and operation. Therefore, the competition of the future mariners' labor market lies mainly on the quality of the talents and the quality of the marine education depends on the diathesis of the mariners. What's more, future navigating and engineering officers in Slovenia are educated at a higher education level at the Faculty of Maritime Studies and Transportation [11]. IMO officially promoted English as the language of the sea in the STCW 95 Convention and Code, so it is also important to use maritime English training for non-native speaking mariners [12]. Nowadays, many new technology and teaching methodologies are utilized on global maritime education and training into the 21st century [13]. The scale and structure of maritime Education has a significant change, and which brings increasingly prominent effects on mariners, maritime education and labor market development itself. The world shipping industry and international nautical labor market turn to eastward, which gives new opportunities and challenges on the nautical education development in China [14].

\section{The Current Situation of the Nautical Education of Undergraduate in Shandong Province}

\subsection{The Small Training Scale of Undergraduate Education}

Nautical education is similar to other engineering courses. It is a kind of multi-level and multi-type education with its own characteristics [15]. The nautical education in China includes three levels of degree: Undergraduate, specialist/vocational, college/vocational. The nautical education and training market underwent explosive growth in the past years of sustained development of economy and prosperity of shipping industry. In 2015, the nautical education and training institutions recruited student 14960 maritime students, including 8193 officers and 6767 Engineers (Electro-technical officers contain), which are shown in detail below Figure 1

In the Figure 1, the up part describes the number of Officers recruited; the middle shows the case of Engineers; the number of the Electro-technical officers is on the bottom.
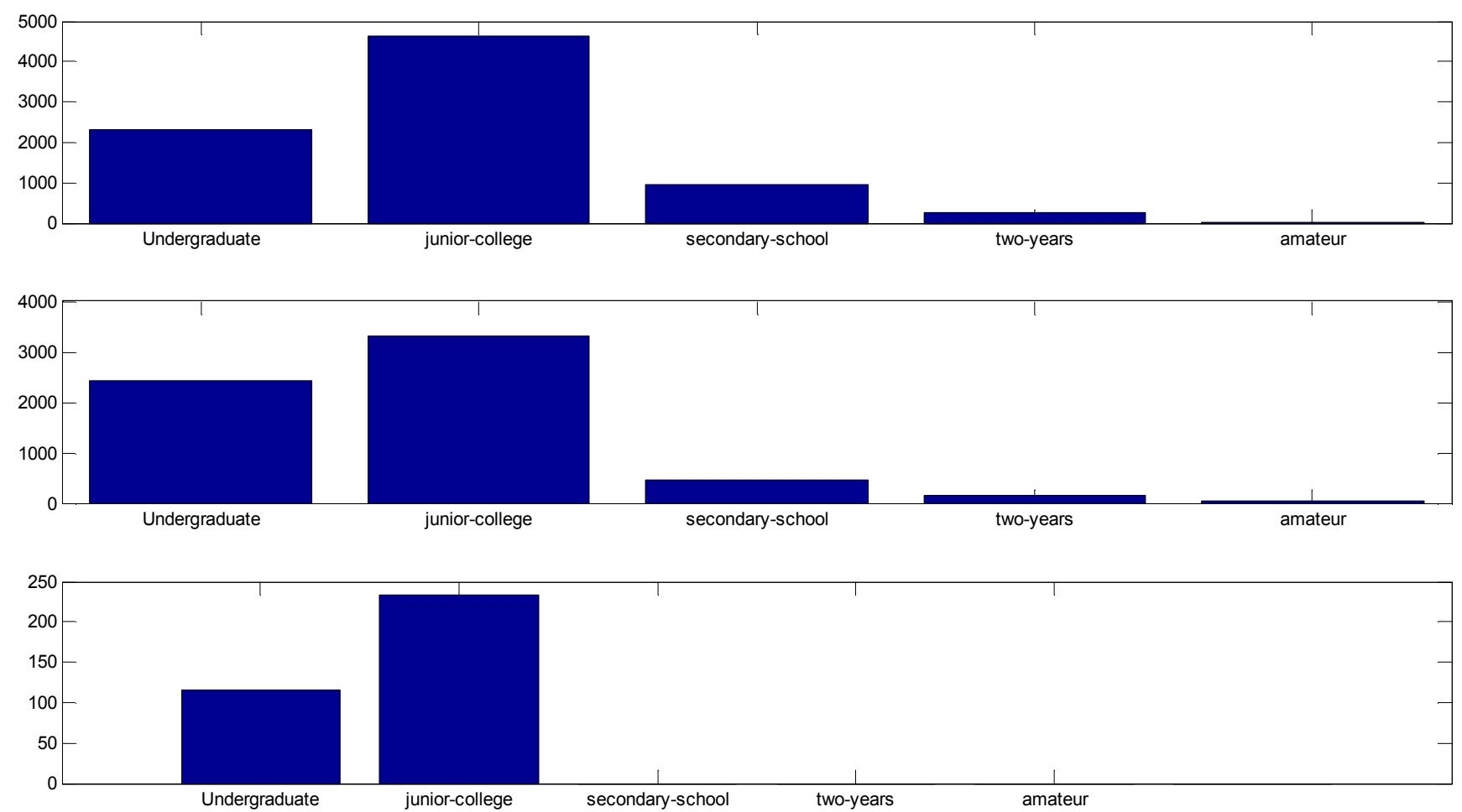

Figure 1. Nautical students recruited in China in 2015. 


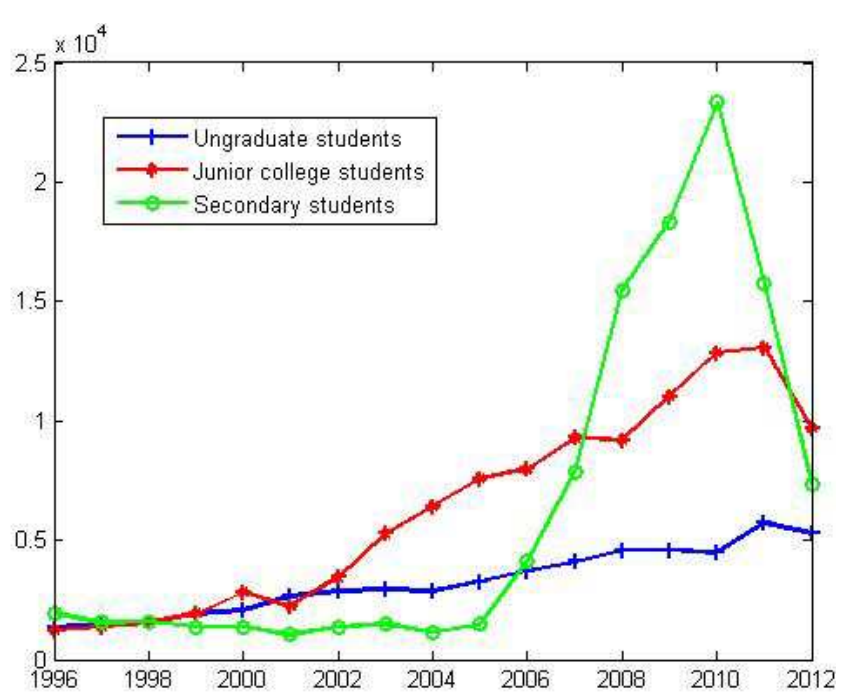

Figure 2. 1996-2012 Nautical students in China.

From 1996 to 2012, many colleges and Universities recruit more nautical students, just like above Figure 2 But we can see that the number has a significantly down trend. Therefore, our nautical education might meet some difficulties.

Table 1. The number of nautical student in China.

\begin{tabular}{llllll}
\hline \multirow{2}{*}{ Major Type } & \multicolumn{6}{l}{ Student number } \\
\cline { 2 - 6 } & $\mathbf{2 0 1 1}$ & $\mathbf{2 0 1 2}$ & $\mathbf{2 0 1 3}$ & $\mathbf{2 0 1 4}$ & $\mathbf{2 0 1 5}$ \\
\hline Navigation & 24251 & 15654 & 11912 & 9321 & 8193 \\
Marine engineering & 19662 & 12192 & 9940 & 7832 & 6767 \\
total & 43913 & 27846 & 21852 & 17153 & 14960 \\
\hline
\end{tabular}

As is shown in the table 1 , the number of nautical student ware reduced from 2011 to 2015 in China. The students with two majors (navigation and marine engineering) were reduced separately.

There had been sixteen crew education and training institutions with 9747 students in Shandong province by the end of January, 2016, including 2 undergraduate universities, 5 academy colleges, 9 special secondary schools. But the undergraduate education grows quite slowly. The two maritime institutions who own undergraduates are Shandong Jiaotong University and Yantai University. The number of nautical undergraduate enrollment in Shandong province is merely 600 in 2015, meanwhile, the total undergraduate students is 1581 , this number is only $16 \%$ of total mariner student in shandong province comparing the national rate is $32 \%$.

\subsection{The Discipline Construction and Resources of the Teaching Staff Are Weak}

The undergraduate education aims to cultivate the nautical talents who can not only engage in work on board but also know about teaching, research andmanagement, which requires the subject diversification and structure rationalization.

Both of the two undergraduate institutions in Shandong province derive from the combination of vocational secondary school and undergraduate institutions (the predecessor of Maritime Institute of Shandong Jiaotong University is Shandong Water Transportation School; the predecessor of the oceanography institute of Yantai University is Shandong Fishery School). The resource of teaching staff is relatively weak and the structure of the teaching staff is irrational in these two institutions. There is a low proportion of professors and doctors. What's more, the average age of the professors and doctors is high. At the same time most teachers do not possess sailing experience and the teachers who own Captain or Chief Engineer certificate of competency is small in amount, which makes it hard for the nautical education to combine theory with practice. As undergraduate institutions, the requirement of degree makes it difficult to recruit some experienced and high-quality captains and chief engineers who do not meet the demand of degree. However, some fresh out of university graduates are not competent enough for teaching because of lack of experience.

The collective advantage of academic leaders on maritime subjects needs to be enhanced. In recent years more and more academic dissertations are published in these two undergraduate institutions. However, many of these theses are lacking in pioneering, significant impact and originality. The social identification of the academic quality is low. The fact proves that only through training of high quality resource of teaching staff can we improve the quality of professional education.

\subsection{A Downward Tendency of the Quality of Candidates}

With the over recruit of students of the higher education in China, each university recruit students batch by batch. Besides Dalian Maritime University, there is a downward tendency of the quality of candidates in other maritime institutions. The downward tendency becomes more distinct after the over recruit.

Secondly, feedback from the labor market influences the quality of enrollment. The attraction of navigation is becoming smaller and smaller because of the decline of the income gap between work on land and on board, the prevalent pirate attacks and the unfair treatment the mariners face. The strike of the financial crisis makes the ship owners cut down on cadets on board, which cannot provide enough opportunity of fieldwork for maritime graduates.

In addition, the problem of the only children needs to be considered. Most of the students are only children, and some of them are spoiled by their parents. In practical courses they are slow to get themselves into a state and are lacking in persistence. What's more, their physical fitness and automatic learning ability is not as good as former students. The only children are short of team spirit and hard-working spirit, which do not agree with the requirement of qualitative mariners.

\subsection{Practice Teaching Is Weak}

There are too few or even without apprentice ships for 
students and the students cannot know more information about the ship after their on board a ship. The laboratory equipment is a little old-fashioned and some equipments and services are inadequate, which influence the effect of practice training enormously. One of the main factors of the weak practice training is the insufficient investment on maritime education.

\subsection{Undergraduates and Specialists Are Two Independent Levels}

However, they both share similar training objectives, similar teaching material and content of courses and similar curriculum provision. Consequently, they both do not possess their own characteristics.

The development of the nautical education of the undergraduates should not be confined to the vocational education which meets the requirement of STCW which is the minimum requirement for the mariners, but instead it should pay more attention to the speculative knowledge for the undergraduate education, such as computer, mathematics and English, through which the students' adaptive capability of confronting the social change can be nurtured.

\section{The Necessity of Developing the Nautical Education of Undergraduates Energetically}

\subsection{Shandong Province Demands the Nautical Education of Undergraduates to Develop Coastal Economic Regions in Shandong Peninsula}

The human resource strategy of coastal economic regions in Shandong Peninsula requires high-calibre maritime administration talents and marine talents, including both specialists and college students but also marine talents who undergo undergraduate education and are equipped with better theoretical basis, stronger adaptability and development potentials. Shandong province is a large province in that it cultivates many crew members. However, it is in no way a strong province on cultivating crew members due to its poor cultivation on high-level personnel. Shandong province does not lag behind any advanced maritime provinces both on scale and quality on training mariners. However, graduates from Shandong province rarely set foot in fields of maritime administration, maritime control and maritime safety legislation, the basic reason of which is a lack of compound talents who owns not only abundant experience on navigation and administration but also profound knowledge about legislation and environmental protection.

\subsection{The Development of Maritime Technology Calls for High-Level Nautical Education}

The development of science and technology brings about great change to maritime technology. The technology of ships are taking the direction of automatization, intelligentization and digitalization, from celestial fixing to GPS (global positioning system) positioning, from paper chart to ECDIS (electronic chart display and information system), from artificial radar plotting to ARPA (automatic radar plotting aid), from Morse communication to GMDSS (global maritime distress and safety system), ..., Integrated bridge system, unattended operation engine room, ship local area network and so on. The officers on board will tackle with plenty of computer terminals such as ECDIS, GPS/DGPS (digital Global Positioning System), AIS (automatic identification system), VDR (voyage data recorder), ARPA, AUTO-0 system, GMDSS, ship local area network, NAVTEX, facsimile machine, loading computer and so on. Instead of the former requirement of "maintain, use, manage and repair", modern ships put forward more requirements to the senior mariners. Mariners, especially officers, should be able to analyze, deal with, judge and make a decision based on information to manage and control the ship scientifically. Captains and Chief Engineers on board modern ships should be equipped with sufficient theories on navigation which demands high-level education.

\subsection{Develop the Nautical Education of Undergraduates and Attract Excellent Source of Students}

The source of students in developed regions who are willing to work on board is becoming fewer and fewer with the increasing enrollment and the rising living standard. Only through hold on to the nautical education of undergraduate, can we attract better source of students. Consequently, we can promote the quality of mariners and accelerate the modernism of navigation.

\section{Some Tips on How to Accelerate the Nautical Education of Undergraduates in Shandong Province}

\subsection{Shandong Province Should Construct a High Level Maritime Teaching Faculty}

Shandong should push forward the management system reform in maritime institutions. Besides, Shandong ought to set up a reasonably structured and talented rank of teachers. The teaching faculty is supposed to draw in mariners who possess undergraduate or higher degree, abundant sailing experience and are well-qualified. Furthermore, maritime institutions are encouraged to expand opportunities to introduce maritime talents. Teacher exchanges between maritime institutions are advocated. A reasonable allocation mechanism of beneficial interactions can be formed by means of the interaction of faculty. Shandong ought to execute relevant policies that are in favor of the construction of maritime faculty, for example, Shandong should formulate provisions on the dual position of maritime professional teachers as soon as possible.

Shandong ought to create preferable conditions for young teachers to uplift their ability. Maritime institutions should 
draw in more talents, especially relevant disciplines on navigation, to optimize the maritime teaching faculty and accommodate to the development of the modernism of shipping industry.

Shandong ought to develop the pluralism of teachers' evaluation system and get rid of highlighting scientific research while belittling teaching, which appeal to the maritime institutions to offer supportive policies, adopt pluralism evaluation criteria according to individual's strong point, bring the ability and potential of talents into full play and create lively academic atmosphere.

\subsection{Shandong Should Optimize Talent Training Scheme and Teaching Materials}

The nautical education of undergraduates should be on the basis of degree education, treat technical education as a fundamental and should not be exam-oriented education. STCW Manila amendment had been carried out in 2012 when Shandong can optimize the training scheme of navigation major once more, innovate curriculum provision, update maritime teaching materials and furnish a syllabus of teaching infrastructure and laboratory equipment reform that is in accordance with international conventions and domestic provisions. Under the guidance of unified training scheme institutions should select state-compiled textbooks according to the different levels of undergraduate and specialist. What's more, as for certain subjects institutions can write textbooks with their own teaching faculty in combination with reality. Institutions ought to intensify courses like English, mathematics, computer and legislation. Furthermore, some optional courses can be offered.

\subsection{Shandong Should Deepen the Reform of Nautical Education and Offer More Practice Opportunities}

Shandong ought to make prospective human resource strategy in the long run, increase cooperation between school and enterprise, carry out order-training and increase opportunities for cadets to be on board a ship. It is hard for institutions to afford the investment and maintenance of specialized vessel for teaching practice, and it can hardly be carried out in the short term. The corporation between school and enterprise as well as between school and school can help to improve the maritime teaching practice condition of undergraduates so as to achieve win-win of mariners' labor market. At the same time, Shandong province can construct its own joint training fleet of ships or even national teaching practice fleet of ships.

\section{Concusion}

To sum up, the maritime nautical education of undergraduate in Shandong province are confronted with both challenges and opportunities. Shandong province ought to promote maritime nautical education of undergraduates energetically, which meets the need of enhancing navigation, developing "a Shandong who is well developed on coastal regions", speeding up the construction of "coastal economic regions in Shandong Peninsula" and developing maritime technology. Relevant apartments, institutions and enterprises should work out the scheme of nautical education's development, draw up relevant policies, support and promote the healthy development of the maritime nautical education of undergraduate in Shandong province.

\section{Acknowledgements}

The authors would like to acknowledge the support from the Teaching reform Foundation of Shandong Jiaotong University [JG201609]; the Jiaotong Education Study Group Program of China [NO.1402-83]; This research was also a part of the Weihai Science and Technology Development Program titled "Development of Mariners E-learning and CBT System Based on Maritime Satellite Communication”.

\section{References}

[1] Huang You-fang. Focus shipping soft power construction and ocean development strategy [J]. Shipping management. 2016. 38 (2): 4-8.

[2] Su Yong-jun. Study on the development of marine higher education in China based on the background of national marine strategy [J]. China Higher Education Research. 2015 (2): $42-45$.

[3] Liu Zheng-jiang. Higher maritime education in China: challenges and Countermeasures [J]. China water transport, 2010 (11): 7-9.

[4] Wu Zhaolin. On connotation of maritime education, function, location and classification - on the meaning and function of Maritime Universities [J] Maritime Education Research, Jan. 2009: 6-11.

[5] Veenstra A W. Nautical education in a changing world: the case of the Netherlands [J]. Marine Policy, 2002, 26 (2): 133-141.

[6] Lin Shaodong. Humanity hypothesis theory on student management in maritime college [J]. Journal of Qingdao ocean shipping mariner college.2016 37 (1): 32-34.

[7] World maritime university of wales. Study on the maritime education and training systems of China, India, Indonesia and the Philippine [C]. 1998, Malmo.

[8] Lewarn B. Maritime education and training-some issues of quality. International conference on matitime education and training. Malmo, 2000: 248-259.

[9] Wang Jingbo, Wang Chuan. The nautical education in Asia contry [J]. Nautical education research. 2009. 23 (1): 28-31.

[10] Huang Youfang. Focus ong shipping soft power construction to realization of maritime power development [J]. Shipping management. 2016. 38 (7): 4-8.

[11] Cop R. Interest in maritime studies at higher education levels in the republic of Slovenia [J]. Pomorstvo: Scientific Journal of Maritime Research, 2007, 21 (1): 69-79.

[12] Yakushechkina Y. Maritime English training for non-native speaking mariners [J]. Proc. of IAMU, 2002, 3: 6-4. 
[13] Muirhead P M P. New technology and maritime training in the 21st century: implications and solutions for MET institutions [J]. WMU Journal of Maritime Affairs, 2004, 3 (2): 139-158.

[14] Sun Peiting, Yao Wenbing. Maritime Education environmental changes and developing countermeasures [J] Maritime Education Research, 2013,01: 1-6.
[15] Dong Fang. Some ideas about maritime undergraduate education in our country [J]. Maritime Education Research. 2005 (3): 1-4. 